\title{
Çarşamba İlçesi (Samsun) Ümitvar Muşmula Genotiplerinin Fiziksel ve Kimyasal
}

\section{Karakterizasyonu}

\section{Eda MARAL GÜRBÜZ1, Saim Zeki BOSTAN2 ${ }^{9}$}

${ }^{1}$ Ordu Üniversitesi, Fen Bilimleri Enstitüsü, Bahçe Bitkileri Anabilim Dalı, Ordu, ${ }^{2}$ Ordu Üniversitesi, Ziraat Fakültesi, Bahçe Bitkileri Bölümü, Ordu

${ }^{1}$ https://orcid.org/0000-0003-0093-4017, ${ }^{2}$ https://orcid.org/0000-0001-6398-1916

$\square:$ szbostan@hotmail.com

\section{ÖZET}

Bu araştırma 2017 ve 2018 yıllarında Samsun ili Çarşamba ilçesinde doğada kendiliğinden yetişen muşmula (Mespilus germanica L.) populasyonu ile üreticiler tarafından yetiştirilen genotipler üzerinde yürütülmüştür. Genotiplerde fiziksel ve kimyasal karakterizasyon yapılmıştır. İki yıllık ortalama değerlere göre meyve ağırlığı 20 g'ın üzerinde olan genotipler değerlendirilmiş ve böylece 20 genotip çalışma kapsamına alınmıştır. İncelenen genotiplerde meyve ağırlığı, meyve eti oranı, suda çözünür kuru madde oranı ve ağaçların verim potansiyeline ait iki yıllık ortalama değerlere göre tartılı derecelendirme yapılmıştır. Değerlendirme sonucunda 5 genotip ümitvar olarak seçilmiştir. Ümitvar genotiplerde ortalama meyve ağırlı̆̆ 28.1-31.6 g, meyve eni 37.4-39.8 mm, meyve boyu 37.3-44.7 mm, meyve eti oranı \%87.9-91.0, meyve eti sertliği \%65.9-89.0, tohum sayısı 4.8-5.1 adet meyve-1, toplam kuru madde oranı \%25.9-28.1, suda çözünür kuru madde miktarı \%10.4-15.2, C vitamini içeriği 24.1-36.7 mg $100 \mathrm{~g}^{-1}$, antioksidan aktivite $22.3-72.0 \mathrm{mmol} 100 \mathrm{~g}^{-1}$, fruktoz içeriği 6202.7-7790.6 mg $100 \mathrm{~g}^{-1}$, malik asit içeriği $1155.8^{-} 1495.4 \mathrm{mg} 100 \mathrm{~g}^{-1}$ ve toplam fenol içeriği $37.6-71.3 \mathrm{mg} 100 \mathrm{~g}^{-1}$ arasında değişmiştir.

\section{Araştırma Makalesi}

$\begin{array}{ll}\text { Makale Tarihçesi } \\ \text { Geliş Tarihi } & : 20.03 .2020 \\ \text { Kabul Tarihi } & : 09.04 .2020\end{array}$

Anahtar Kelimeler

Mespilus gemanica

Genotip

Seleksiyon

Pomoloji

\section{Physical and Chemical Characterization of Promising Medlar Genotypes from Çarşamba District (Samsun province, Turkey)}

\section{ABSTRACT}

This study was carried out on the medlar genotypes (Mespilus germanica L.) grown in Çarşamba district of Samsun province of Turkey in 2017 and 2018. The genotypes physical and chemical traits were examined. Genotypes with fruit weight over $20 \mathrm{~g}$ were evaluated based on the two-year average values and thus 20 genotypes were included in the study. In the genotypes, the "Weighted-Rankit Scale" was made according to the two-year average values of fruit weight, fruit flesh ratio, soluble solid content and yield potential of the trees. Result indicated that 5 studied genotypes were found to be promising. In the promising genotypes, fruit weight ranged between 28.1-31.6 g, fruit width $37.4-39.8 \mathrm{~mm}$, fruit length $37.3-44.7 \mathrm{~mm}$, fruit flesh ratio 87.9-91.0\%, fruit flesh firmness $65.9-89.0 \%$, seed number 4.8-5.1 per fruit, total dry matter 25.9-28.1\%, soluble solid content 10.4-15.2\%, vitamin C 24.1-36.7 mg $100 \mathrm{~g}^{-1}$, antioxidant activity $22.3-72.0 \mathrm{mmol}$ $100 \mathrm{~g}^{-1}$, fructose content $6202.7-7790.6 \mathrm{mg} 100 \mathrm{~g}^{-1}$, malic acid content $1155.8^{-1495.4} \mathrm{mg} 100 \mathrm{~g}^{-1}$ and total phenol content $37.6-71.3 \mathrm{mg} 100 \mathrm{~g}^{-1}$

\section{Research Article}

$\begin{array}{ll}\text { Article History } & \\ \text { Received } & : 20.03 .2020 \\ \text { Accepted } & : 09.04 .2020\end{array}$

\section{Keywords \\ Mespilus gemanica}

Genotype

Selection

Pomology

To Cite: Maral Gürbüz E, Bostan SZ 2020. Çarşamba İlçesi (Samsun) Ümitvar Muşmula Genotiplerinin Fiziksel ve Kimyasal Karakterizasyonu. KSÜ Tarım ve Doğa Derg 23 (4): 816-823. DOI: 10.18016/ksutarimdoga.vi.692052.

\section{GİİŞ}

Anavatanı Avrupa ve Batı Asya olan muşmula (Mespilus germanica), Türkiye'de Karadeniz, Ege ve Marmara Bölgeleri'nde doğada yabani olarak yetişir (Davis, 1972). Daha çok sınır ağacı şeklinde bahçe kenarlarında, ev bahçelerinde, orman ve yol kenarlarında dağınık halde bulunmaktadır (Bostan ve İslam, 2007).

Muşmula yetiştiriciliğinin ticari olarak yapıldığı Almanya ve Hollanda gibi ülkelerde meyvesi iri olan 
bazı çeşitler tescillenmiştir. Dünyada az sayıdaki tescilli ticari çeşitlerin yanı sıra, Türkiyede de ilk olarak 1993 yılında 'Ístanbul' ve 'Italyan' adlı yerel çeşitler tescil edilmiş daha sonra 2014 yılında ise Atatürk Bahçe Kültürleri Merkez Araştırma Enstitüsü tarafından “Akçakoca $77^{\circledR}$ ” muşmula çeşidi tescillenerek üreticilerin hizmetine sunulmuştur (Yılmaz, 2015).

Son yıllarda besin değerinin yüksek olması ve alternatif tıpta kullanımı özellikleri yanı sıra yeni damak tadı arayışı nedeniyle yabani meyvelere ilgi artış göstermiştir (Bostan ve İslam, 2007). Günümüzde birçok yabani meyvenin kültüre alınma işlemi hızla devam etmektedir.

Türkiyede 2019 yılı içerisinde meyve veren 245.700 adet muşmula ağacindan toplam 4.790 ton üretim sağlanmıştır. Aynı yıl Karadeniz tarım bölgesi içinde Samsun ili meyve veren ağaç varlığı bakımından Sinop ilinden sonra ikinci, üretimde ise birinci surada yer almıştır (TÜİK, 2020). Kapama muşmula bahçesi yok denecek düzeyde olduğunudan, gerek ağaç sayısı varlığı ve gerekse üretim miktarının, ulaşllamayan yerlerdeki ağaçlar nedeniyle daha fazla olduğu tahmin edilmektedir.

Yumuşak çekirdekli bir meyve türü olan muşmula çalı formunda yüksekliği 3-7 m arasında, küçük taç yapısına sahip, kış aylarında yaprağını döken, yabani formları dikenli, kültür formları ise dikensiz bir bitkidir. Ağacı uzun ömürlü olup yüz yıldan fazla yaşayabilmektedir (Phipps ve ark., 2003). Polifenoloksidaz yönünden yüksek değere sahip olan meyvenin yenilebilmesi için meyve etinin kahverengileşmesi beklenmelidir (Demir, 2006). Meyveleri hasattan bir süre sonra olgunlaştırılıp yenilebilen olgunlukta kahverengimsi renkte, tatlı iken; yeni hasat edilen meyveler açık renkli, boğucu, sert ve buruktur. Meyvedeki tohum sayısı genellikle beş adettir. Ağacın çiçeklenme zamanı bahar sonu veya yaz başına denk gelirken (mayıs-haziran) meyveler eylül-ekim aylarında hasat edilir (Anonim, 2018).

Muşmula zengin vitamin ve mineral içeriğine sahip meyveleri yanında süs bitkisi ve tibbi bitki olarak da değerlendirilmektedir. Meyveleri çeşitli şekerler, organik asitler, pektin, potasyum, C vitamini ve az miktarda A, B1 ve B2 vitamini içerir (Hacıseferoğulları ve ark., 2005).

Gözlemlerimize göre sağlık açısından birçok faydası olduğuna inanılan Karadeniz bölgesinde muşmula; pekmez, sirke, reçel gibi ürünler şeklinde yıl boyunca tüketilmektedir. Bunun yanında muşmulanın yaprağından yapılan çayın ağrı giderici özellikte olduğuna da inanılmaktadır.

Türkiyede muşmula seleksiyonu üzerine yapılan çalışmalar sınırlı sayıda olup, meyvenin kimyasal bileşiminin daha fazla araştırılması ve alternatif tıpta kullanımı son zamanlarda meyveye olan ilgiyi artırmış ve çalışmalar bu doğrultuda hız kazanmıştır.

Islah çalışmalarının yapı taşlarını oluşturan genetik çeşitliliğin sürdürülebilmesi sahip olduğumuz gen kaynaklarının korunması ve geleceğe aktarılması ile mümkündür. Kültüre alınmayan ve kendi yetiştirildiği yöreler dışında tanınmayan çoğu bitki gibi muşmula da koruma altına alınmaz ise gelecekte kaybolabilecek türler arasindadır (Ekim ve ark., 2000).

Türkiye sahip olduğu coğrafi konumu ve elverişli iklimi sayesinde birçok bitki türünün anavatanı olmanın yanı sıra farklı ekolojilere adapte olmuş çoğu bitki türüne de ev sahipliği yapmaktadır. Gelişen dünya nüfusu gida ve beslenme sorunu başta olmak üzere birçok sorunu da beraberinde getirmiş, aynı zamanda yeni yerleşim yerleri oluşturmaya çalışan insanımız bilinçsiz bir şekilde genetik erozyona da sebep olmuştur. Buna rağmen genetik çeşitlilik yönünden oldukça geniş ve bakir durumda olan Türkiyede doğal meyve genetik kaynaklarının çeşit ıslahında kullanılması meyveciliğimizin gelişmesi açısından gereklidir. Yapılan seleksiyonlar yöresel çeşit ve genotiplerin belirlenmesinde büyük rol oynamanın yanı sira bu konuda yapılacak araştırmalara da ışık tutacaktır. Meyve genetik kaynaklarındaki çeşitliliğin belirlenmesi, toplanması ve korunması Türkiye meyveciliği için oldukça önem arz etmektedir.

$\mathrm{Bu}$ çalışmanın amacı da Samsun ili Çarşamba ilçesindeki doğal ortamda yetişen muşmula genotiplerini ve bunlar arasındaki varyasyonu tespit etmek, fiziksel ve kimyasal yönden karakterizasyonunu yapmak ve çeşit adayı ümitvar genotipleri belirlemektir.

\section{MATERYAL ve METOT}

\section{Materyal}

Bu çalışma Samsun ilinin muşmulada en fazla üretim değerine sahip Çarşamba ilçesinde yürütülmütür. Araştırma materyalini doğada kendiliğinden yetişmekte olan ve çiftçiler tarafindan aşılanan

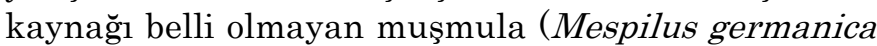
L.) populasyonu oluşturmuştur.

Araştırma 2017 ve 2018 yıllarında Samsun İli Çarşamba İlçesinde, populasyonun ve varyasyonun yoğun olduğu, Aşağı Donurlu, Alibeyli, Demirli, Kuşçulu, Muşçalı, Oymalı, Sığırtmaç, Yamanlı ve Yaycılar mahallelerinde yürütülmüştür.

\section{Metot}

\section{Arazi çalışmaları}

Çalışmanın ilk yılında Samsun İli Çarşamba ilçesindeki mevcut muşmula popülasyonunun tespiti için İlçe Tarım ve Orman Müdürlüğü, Çarşamba Ziraat Odası, önder çiftçiler ve muhtarlarla yapılan görüşmeler doğrultusunda bir ön değerlendirme 
çalışması yapılmıştır. Araştırma 2017 Eylül ayında başlatılmış olup ağaçların meyveli olduğu döneminde ön gezi düzenlenerek ağaç üzerindeki meyve verimleri incelenmiştir.

Genotiplerin seçiminde ortalama meyve ağırlığ 20 g'ın üzerinde olan ve aynı zamanda taç gelişimi alanına göre, göreceli olarak en az orta düzeyde verimli olan (tacın yaklaşık \% 50'sinde meyve bulunan) ağaçlardan örnekler alınmıştır. Buna göre, ilk yıl en az orta düzeyde verimli olan genotipler arasindan meyve ağırlığ 20 g'ın üzerinde olan 23 genotip belirlenmiş ve bu genotiplerden ikinci yll da örnekler alınarak değerlendirilmiştir. Genotiplerin meyve ağırlıklarına ait iki yıllık ortalama değerlere göre ağırlığı 20 g'ın altında kalan 3 genotip elenmiş ve değerlendirmeye 20 genotiple devam edilmiştir.

Ağaçların verim potansiyelinin belirlenmesi amacıyla, her bir genotipe ait ağacın taç hacminde verim potansiyeli göreceli olarak belirlenmiştir. Buna göre, verim potansiyeli taç hacminin toplamda yaklaşı $\%$ 50'si kadar bir alanda meyve yükü olma durumunda "orta" (1 puan), taç hacminin toplamda yaklaşık \% 75'i kadar bir alanda meyve yükü olma durumunda "yüksek" (3 puan) ve taç hacminin toplamda tamamina yakın bir alanda meyve yükü olma durumunda ise "çok yüksek" (5 puan) olarak değerlendirilmiş olup genotiplerin bu bakımdan iki yıl almış olduğu puanların ortalaması tartılı derecelendirmede kullanılmıştır.

\section{Fiziksel ve kimyasal karakterizasyon}

Meyve örnekleri, her iki yıl ekim ayında meyve etinin çoğunluğunun beyaz olduğu dönemde toplanmıştır. Analizler genotiplerden ağacı temsil edecek şekilde alınarak 20 adet meyvede yapılmıştır. Fiziksel ve kimyasal analizler tüketim olumu aşamasında (buruk tadın azaldığı ve meyve etinin yaklaşık \% 50'sinin kahverengiye dönüştüğü dönem) yapılmış olup meyvelerin bu döneme gelebilmesi için, laboratuvar koşullarında oda sıcaklığında bekletilmiştir (Yılmaz, 2015).

Muşmula genotiplerinde özelliklerin belirlenmesinde Özkan ve ark. (1997), Bostan (2002), Hacıseferoğulları ve ark. (2005), Bostan ve İslam (2007), Gülçin ve ark. (2011), Ercişli ve ark. (2012), Yılmaz ve Gerçekçioğlu (2013), Canbay Seçilmiş ve ark. (2015), Yılmaz (2015), Közen ve Bostan (2016), Akın ve Bostan (2018), Cevahir ve Bostan (2018) ve Uzun ve Bostan (2019)'dan yararlanılmıştır.

Meyve ve tohum ağırlığı 0.01 g'a duyarlı terazi ile (Dikomsan KD-TBC), meyve boyutları ile çiçek çukur genişliği ve derinliği $0.01 \mathrm{~mm}$ 'ye duyarlı kumpasla (MaxEkstra/150 mm), meyve iriliği meyve eni ve boyu değerlerinin toplamının ikiye bölünmesiyle ((ME+MB)/2), meyve hacmi suda taşırma yöntemiyle (cc), tohum sayısı her bir meyvedeki sağlam ve gelişmiş olan tohumların sayılmasıyla (adet meyve-1), meyve kabuk rengi: değerleri $\left(\mathrm{L}^{*}, \mathrm{a}^{*}, \mathrm{~b}^{*}\right.$, Chroma, Hue açısı) meyvenin ekvatoral bölgesinde renk ölçerle (Konica Minolta Europe CR-400), meyve eti sertliği dijital sertlik ölçerle (Agrosta ${ }^{\circledR}$ 100Field model, Fransa) yüzde olarak belirlenmiş; meyve eti oranı meyve ağırlı̆̆ından toplam tohum ağırlığının çıkartılmasıyle elde edilen değerin 100 ile çarpılması ve meyve ağırlığına bölünmesiyle (\%); toplam kuru madde oranı da 3-5 g meyve örneğinin $105{ }^{\circ} \mathrm{C}$ sıcaklıkta etüvde sabit ağırlık elde edilinceye kadar kurutulması sonucunda, ilk tartım ile son tartım değeri farkının ilk tartım değerine bölünmesi ve sonucun 100 ile çarpılmasıyla (\%) hesaplanmış ve ortalama değer olarak ifade edilmiştir.

Suda çözünür çuru madde miktarı homojen meyve suyunda el refraktometresiyle (\%, Greinorm 0-80 Brix); asitlik titrasyon yöntemiyle (\%); $\mathrm{pH}$ potansiyometrik olarak $\mathrm{pH}$-metreyle; $\mathrm{C}$ vitamini içeriği askorbik asit testi kitleri (Merck 116981) kullanılarak reflectoquant cihazıyla (mg 100g-1); toplam fenol içeriği Folin-Ciocalteu's kimyasalı kullanılarak (mg 100g-1); toplam antioksidan aktivite DPPH yöntemiyle (mmol 100g-1); organik asit ve şeker içeriği (mg 100g-1) HPLC cihazıyla belirlenmiştir.

\section{Tartılı derecelendirme}

Tartılı derecelendirme genotiplerin meyve ağırlığı, meyve eti oranı, ağacın verim potansiyeli ile suda çözünür kuru madde miktarına ait 1 . ve 2 . yıl (2017 ve 2018) değerlerinin ortalamalarına göre yapılmıştır (Çizelge 1).

Genotiplerin tartılı derecelendirmede her bir özellik bakımından aldığı puanlar ile toplam puanlar hesaplanmıştır.

\section{BULGULAR ve TARTIŞMA}

Çalışmanın ilk yılında muşmula populasyonunun yoğun olduğu 9 mahallede, hasat döneminde ortalama meyve ağırlığı 20 g'ın üzerinde olan ve göreceli olarak en az orta düzeyde verimli olan 23 genotipten meyve örnekleri alınmış olup ikinci yıl alınan meyve örneklerinde iki yıllık ortalama verilere göre meyve ağırlığı 20 g'ın altında olan 3 genotip elenmiş ve çalışmaya 20 genotiple devam edilmiştir. Buna göre Kuşçulu mahallesi ikinci yıl çalışma kapsamından çıkarılmıştır (Çizelge 2).

20 genotipin pomolojik özelliklerine ait iki yıllık ortalama değerler Çizelge 3 ve Çizelge 4'de sunulmuştur.

\section{Genotiplerin Fiziksel Özellikleri}

Meyve ağırlığı 20.0 g'ın üzerinde olan 20 genotipte meyve ağırlığ $20.0 \mathrm{~g}$ (55ÇŞB17) ile $31.6 \mathrm{~g}$ (55ÇŞB12); meyve eni $32.2 \mathrm{~mm}$ (55ÇŞB17) ile $39.8 \mathrm{~mm}$ (55ÇŞB08), meyve boyu 35.2 (55ÇŞB03) ile $44.7 \mathrm{~mm}$ (55ÇŞB10), 
meyve eti sertliği \%46.3 (55ÇŞB17) ile \%90 (55ÇŞB22), meyve eti oranı \%85.4 (55ÇŞB17) ile \% 91.2 (55ÇŞB11) ve toplam kuru madde oranı \%24.6 (55ÇŞB15) ile \%32.0 (55ÇŞB05) arasında değişmiştir (Çizelge 3).

Çizelge 1. Değiştirilmiş tartılı derecelendirme tablosu (Yılmaz, 2015; Közen ve Bostan, 2016’dan değiştirilmiştir)

Table 1. Modified "Weighted-Scaled" table

\begin{tabular}{|c|c|c|c|c|}
\hline $\begin{array}{l}\text { Özellikler } \\
\text { (Traits) }\end{array}$ & $\begin{array}{l}\text { Ağırlıklı Puan } \\
\text { (Relative point) }\end{array}$ & $\underset{(\text { Class })}{\text { Sinıf Aralığ1* }}$ & $\begin{array}{l}\text { Sinif Puanı } \\
\text { (Class point) }\end{array}$ & $\begin{array}{l}\text { Toplam Puan } \\
\text { (Total point) }\end{array}$ \\
\hline $\begin{array}{l}\text { Meyve ağırlı̆̆ı }(\mathrm{g}) \\
\text { (Fruit weight) }\end{array}$ & 40 & $\begin{array}{c}\geq 28.0 \\
23.0-27.9 \\
\leq 22.9\end{array}$ & $\begin{array}{l}5 \\
3 \\
1\end{array}$ & $\begin{array}{c}200 \\
120 \\
40\end{array}$ \\
\hline $\begin{array}{l}\text { Meyve eti oranı }(\%) \\
\text { (Flesh ratio) }\end{array}$ & 25 & $\begin{array}{c}\geq 90.0 \\
88.6-89.9 \\
\leq 88.5\end{array}$ & $\begin{array}{l}5 \\
3 \\
1 \\
\end{array}$ & $\begin{array}{c}125 \\
75 \\
25 \\
\end{array}$ \\
\hline $\begin{array}{l}\text { Ağacın verim potansiyeli } \\
\text { (Yield potential) }\end{array}$ & 25 & $\begin{array}{c}\text { Çok Yüksek } \\
\text { Yüksek } \\
\text { Orta }\end{array}$ & $\begin{array}{l}5 \\
3 \\
1\end{array}$ & $\begin{array}{c}125 \\
75 \\
25 \\
\end{array}$ \\
\hline $\begin{array}{l}\text { Suda çözünür kuru madde miktarı (\%) } \\
\text { (Soluble solid content) }\end{array}$ & 10 & $\begin{array}{c}\geq 13.8 \\
12.1-13.7 \\
\leq 12.0\end{array}$ & $\begin{array}{l}5 \\
3 \\
1 \\
\end{array}$ & $\begin{array}{l}50 \\
30 \\
10 \\
\end{array}$ \\
\hline
\end{tabular}

TOPLAM 100

Sınıf aralık değerleri populasyona ait iki yıllık (2017 ve 2018) ortalama değerler üzerinden en yüksek ve en düşük değerler arasındaki farkın sınıf sayısına bölünmesiyle hesaplanmıştır.

Class range values are calculated by dividing the difference between the highest and lowest values over the two-year (2017 and 2018) average values of the population by the number of classes.

Çizelge 2. Arazi gezileri yapılan lokasyonlar ve belirlenen genotipler

Table 2. Locations of field trips and genotypes

\begin{tabular}{ll}
$\begin{array}{l}\text { Çalışma alanları } \\
\text { (Locations) }\end{array}$ & $\begin{array}{l}\text { Genotipler } \\
\text { (Genotypes) }\end{array}$ \\
\hline Aşağı Donurlu & 55ÇŞB01, 55ÇŞB02, 55ÇŞB03 \\
\hline Alibeyli & 55ÇŞB19 \\
\hline Demirli & 55ÇŞB05, 55ÇŞB06, 55ÇŞB07, 55ÇŞB08, 55ÇŞB09, 55ÇŞB10, 55ÇŞB11, 55ÇŞB12, 55ÇŞB13 \\
\hline Kuşçulu & - \\
\hline Muşçalı & 55ÇŞB15, 55ÇŞB16, 55ÇŞB17 \\
\hline Oymalı & 55ÇŞB22 \\
\hline Siğırtmaç & 55ÇŞB23 \\
\hline Yamanlı & 55ÇŞB20 \\
\hline Yaycılar & 55ÇŞB21 \\
\hline
\end{tabular}

\section{Genotiplerin Kimyasal Özellikleri}

Meyve ağırlığı 20.0 g'ın üzerinde olan 20 genotipte, suda çözünür kuru madde miktarı \%10.4 (55ÇŞB09)

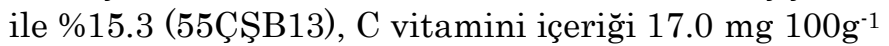

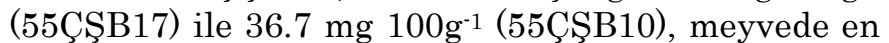
fazla bulunan şeker olan fruktoz içeriği $6202.7 \mathrm{mg}$ $100 \mathrm{~g}^{-1}$ (55ÇŞB08) ile $7843.1 \mathrm{mg} 100 \mathrm{~g}^{-1}$ (55ÇŞB01), meyvede en fazla bulunan asit olan malik asit içeriği $775.2 \mathrm{mg} 100 \mathrm{~g}^{-1}$ (55ÇŞB15) ile $1498.3 \mathrm{mg} 100 \mathrm{~g}^{-1}$ (55ÇŞB11), toplam antioksidan aktivite $16.8 \mathrm{mmol}$ $100 \mathrm{~g}^{-1}$ (55ÇŞB5) ile $191.0 \mathrm{mmol}^{100 \mathrm{~g}^{-1}}$ (55ÇŞB21) ve toplam fenol içeriği de $23.0 \mathrm{mg}^{100 \mathrm{~g}^{-1}}$ (55ÇŞB05) ile $79.7 \mathrm{mg} \quad$ 100g $^{-1}$ (55ÇŞB11) arasında değişim göstermiştir (Çizelge 4).

\section{Tartılı Derecelendirme Sonuçları}

Araştırmada meyve ağırlığı, meyve eti oranı, ağacın verim potansiyeli ve suda çözünür kuru madde gibi önemli görülen bazı meyve özellikleri yönünden tartılı derecelendirme yapılmıştır (Cizelge 1). Genotiplerin toplam puanları her özellik için belirlenen sınıf aralık puanı ile özelliğin değer puanının çarpılması ve her özelliğe ait puanların toplanması ile hesaplanmıştır (Çizelge 5).

Tartılı derecelendirme sonuçlarına göre, genotipler toplamda 100 ile 480 arasında puan almıştır. 400 ve üzerinde puan alan genotiplerin çeşit adayı olma bakımından potansiyeli yüksek, 300-380 arasındakilerin orta ve 300'ün altındakilerin de az olarak değerlendirilmiş ve buna göre 400 ve üzerinde toplam puan alan, sırasıyla, 55ÇŞB10, 55ÇŞB09, 55Ç\$̧B12, 55ÇŞB08 ve 55ÇŞB13 nolu genotipler ümitvar olarak seçilmiştir (Şekil 1).

Türkiye'de muşmulada seleksiyon ıslahı konusunda yapılan çalışmaların sayısı oldukça azdır. Bu çalışmalar sonucunda Tokat ili merkezinden 5 ümitvar 
Çizelge 3. Genotiplerin fiziksel özelliklerine ait ortalama değerler

Table 3. Average values of the physical properties of genotypes

\begin{tabular}{|c|c|c|c|c|c|c|c|c|c|c|c|c|c|c|c|c|c|}
\hline $\begin{array}{l}\text { Genotip } \\
\text { Genotype }\end{array}$ & MA & ME & MB & MI & $\mathrm{MH}$ & ÇÇG & ÇÇD & MES & MEO & $\mathrm{TS}$ & TA & TKM & $L^{*}$ & $a^{*}$ & $b^{*}$ & C & h \\
\hline 55ÇŞB01 & 23.8 & 35.5 & 36.8 & 36.2 & 22.5 & 22.2 & 9.5 & 81.3 & 88.5 & 5.0 & 2.5 & 26.9 & 69.4 & 5.9 & 25.0 & 25.8 & 77.3 \\
\hline 55ÇŞB02 & 27.0 & 37.5 & 36.1 & 36.8 & 27.8 & 23.3 & 9.2 & 76.5 & 88.7 & 5.0 & 2.9 & 28.1 & 70.1 & 6.3 & 22.8 & 23.8 & 75.2 \\
\hline 55ÇŞB03 & 21.5 & 36.1 & 35.2 & 35.7 & 22.9 & 22.0 & 7.9 & 80.5 & 89.9 & 4.9 & 2.4 & 28.8 & 71.6 & 6.1 & 25.7 & 26.6 & 76.9 \\
\hline 55ÇŞB05 & 23.6 & 34.9 & 40.1 & 37.5 & 23.9 & 18.1 & 10.4 & 84.0 & 86.9 & 5.0 & 3.0 & 32.0 & 79.1 & 8.5 & 23.8 & 25.4 & 72.0 \\
\hline 55ÇŞB06 & 27.1 & 37.9 & 39.5 & 38.7 & 28.4 & 19.7 & 9.8 & 70.6 & 90.0 & 5.0 & 2.6 & 28.6 & 82.8 & 6.6 & 24.1 & 25.1 & 75.1 \\
\hline 55ÇŞB07 & 20.2 & 33.4 & 35.9 & 34.7 & 20.7 & 22.4 & 7.4 & 76.7 & 87.7 & 5.0 & 2.5 & 26.1 & 85.1 & 6.2 & 26.2 & 26.9 & 76.7 \\
\hline 55ÇŞB08 & 30.1 & 39.8 & 37.3 & 38.6 & 29.1 & 20.9 & 10.5 & 65.9 & 89.3 & 5.0 & 3.2 & 27.7 & 84.7 & 7.2 & 23.8 & 25.0 & 73.6 \\
\hline 55ÇŞB09 & 28.1 & 37.5 & 43.1 & 40.3 & 25.9 & 19.4 & 10.8 & 89.0 & 90.8 & 4.8 & 2.6 & 27.6 & 89.1 & 5.9 & 27.0 & 27.7 & 77.1 \\
\hline 55ÇŞB10 & 28.9 & 37.4 & 44.7 & 41.1 & 27.8 & 20.1 & 9.3 & 80.8 & 90.8 & 5.0 & 2.6 & 25.9 & 90.5 & 6.3 & 25.7 & 26.5 & 76.0 \\
\hline 55ÇŞB11 & 28.6 & 37.9 & 42.6 & 40.3 & 29.3 & 20.8 & 9.8 & 82.7 & 91.2 & 5.0 & 2.4 & 29.4 & 92.5 & 5.8 & 24.7 & 25.4 & 76.5 \\
\hline 55ÇŞB12 & 31.6 & 39.0 & 44.1 & 41.6 & 32.1 & 21.9 & 9.1 & 82.7 & 91.0 & 5.1 & 2.7 & 27.7 & 94.4 & 6.2 & 25.0 & 25.8 & 75.8 \\
\hline 55ÇŞB13 & 29.7 & 39.0 & 41.4 & 40.2 & 29.4 & 21.9 & 9.4 & 71.0 & 87.9 & 5.0 & 3.7 & 28.1 & 92.0 & 6.8 & 22.1 & 23.2 & 73.5 \\
\hline 55ÇŞB15 & 21.1 & 34.1 & 36.7 & 35.4 & 21.7 & 17.1 & 10.1 & 66.9 & 86.9 & 5.0 & 2.8 & 24.6 & 97.8 & 5.3 & 29.0 & 29.5 & 78.5 \\
\hline 55ÇŞB16 & 22.4 & 34.1 & 36.1 & 35.1 & 22.8 & 18.0 & 9.6 & 52.7 & 85.7 & 5.0 & 3.4 & 28.9 & 97.3 & 5.1 & 26.7 & 27.3 & 77.7 \\
\hline 55ÇŞB17 & 20.0 & 32.2 & 35.5 & 33.9 & 20.7 & 17.1 & 9.3 & 46.3 & 85.4 & 5.0 & 3.0 & 26.3 & 99.4 & 7.0 & 26.9 & 27.9 & 75.0 \\
\hline 55ÇŞB19 & 21.2 & 33.2 & 36.0 & 34.6 & 21.4 & 21.1 & 8.1 & 74.9 & 89.5 & 5.0 & 2.2 & 26.8 & 101.4 & 5.7 & 23.3 & 24.1 & 75.6 \\
\hline 55ÇŞB20 & 22.4 & 34.2 & 37.0 & 35.6 & 21.5 & 17.5 & 9.0 & 74.2 & 88.1 & 4.9 & 2.6 & 28.4 & 101.8 & 7.3 & 23.9 & 25.1 & 73.3 \\
\hline 55ÇŞB21 & 22.6 & 35.0 & 37.7 & 36.4 & 25.0 & 22.8 & 6.9 & 89.5 & 89.7 & 5.0 & 2.7 & 28.1 & 103.7 & 6.2 & 22.8 & 23.6 & 74.6 \\
\hline 55ÇŞB22 & 27.0 & 36.7 & 38.7 & 37.7 & 26.6 & 20.8 & 8.1 & 90.0 & 88.7 & 5.0 & 3.1 & 31.1 & 104.1 & 5.7 & 23.1 & 23.9 & 75.6 \\
\hline 55ÇŞB23 & 23.3 & 34.1 & 38.1 & 36.1 & 23.8 & 18.8 & 8.8 & 84.3 & 89.6 & 4.9 & 2.3 & 32.0 & 104.7 & 5.0 & 21.8 & 22.5 & 76.6 \\
\hline MA Meyv & Ağırlığ & $1(\mathrm{~g}) / 1$ & uit we & ight & & & & & ÇÇD & & & $\overline{\text { ur Der }}$ & inliği (n & 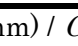 & $\overline{y x d e p}$ & & \\
\hline ME & Eni & & it & & & & & & MES & & & & & & & & \\
\hline Meyv & Boyu & $\mathrm{mm}) / 1$ & ruit les & ngth & & & & & MEO & & je & Orar & (\%) & esh $r$ & & & \\
\hline Meyv & iriliği & $\mathrm{mm}) /$ & ruit si & & & & & & $\mathrm{TS}$ & & & ayısı / S & Ded & nber & & & \\
\hline Meyv & Hacmi & $(\mathrm{ml}) /$ & ruit vo & lume & & & & & TA & & um & ğırlığı & g) / Sec & weig & & & \\
\hline Çiçek & Çukur & Geniş̧li & $\mathrm{i}(\mathrm{mm})$ & / Caly & vidth & & & & TKM & & lam & uru M & dde (\%) & / Tota & dry mat & & \\
\hline
\end{tabular}

Çizelge 4. Genotiplerin kimyasal özelliklerine ait ortalama değerler

Table 4. Average values of the chemical properties of genotypes

\begin{tabular}{|c|c|c|c|c|c|c|c|c|c|c|c|c|}
\hline $\begin{array}{l}\text { Genotip } \\
\text { Genotype }\end{array}$ & $\mathrm{pH}$ & SÇKM & $\mathrm{TA}$ & C Vit. & SAK & GL & FR & AK & SA & MA & SÜA & $\mathrm{TF}$ \\
\hline 55ÇŞB01 & 9.1 & 13.7 & 0.7 & 295.0 & 388.9 & 5147.1 & 7843.1 & 30.1 & 3.6 & 1185.0 & 327.4 & 38.1 \\
\hline 55ÇŞB02 & 9.2 & 13.0 & 0.6 & 236.0 & 290.9 & 5350.2 & 7813.5 & 17.8 & 14.5 & 1119.8 & 221.2 & 23.1 \\
\hline 55ÇŞB03 & 9.1 & 12.0 & 0.6 & 301.0 & 261.4 & 5143.8 & 7626.9 & 22.7 & 16.6 & 1068.6 & 279.3 & 28.5 \\
\hline 55Ç\$̧B05 & 9.4 & 12.6 & 0.4 & 245.0 & 291.2 & 5129.8 & 7560.1 & 16.8 & 28.2 & 861.4 & 207.8 & 23.0 \\
\hline 55ÇŞB06 & 9.2 & 11.6 & 0.5 & 262.0 & 291.4 & 4458.4 & 6866.5 & 21.0 & 5.5 & 938.6 & 221.9 & 52.6 \\
\hline 55ÇŞB07 & 9.1 & 12.0 & 0.7 & 293.0 & 344.1 & 5047.6 & 7662.8 & 24.0 & 15.2 & 1234.4 & 338.8 & 52.9 \\
\hline 55Ç\$̧B08 & 8.7 & 10.8 & 0.9 & 324.0 & 306.8 & 4253.1 & 6202.7 & 42.5 & 15.2 & 1190.6 & 400.6 & 51.3 \\
\hline 55ÇŞB09 & 9.1 & 10.4 & 0.6 & 334.0 & 263.9 & 5022.7 & 7064.3 & 42.3 & 7.6 & 1155.8 & 252.6 & 71.3 \\
\hline 55ÇŞB10 & 8.6 & 12.4 & 0.8 & 367.0 & 458.8 & 5252.3 & 7540.8 & 72.0 & 9.7 & 1495.4 & 351.7 & 70.8 \\
\hline 55ÇŞB11 & 8.8 & 11.6 & 0.8 & 283.0 & 475.8 & 4461.6 & 6720.5 & 44.6 & 31.2 & 1498.3 & 434.2 & 79.7 \\
\hline 55ÇŞB12 & 8.8 & 13.8 & 0.9 & 281.0 & 425.9 & 4716.3 & 6968.9 & 39.4 & 15.4 & 1463.0 & 369.4 & 37.6 \\
\hline 55ÇŞB13 & 8.9 & 15.2 & 0.9 & 241.0 & 285.7 & 5516.8 & 7790.6 & 22.3 & 9.0 & 1229.9 & 299.9 & 53.8 \\
\hline 55ÇŞB15 & 9.0 & 13.8 & 0.5 & 236.0 & 337.7 & 4027.8 & 6381.8 & 27.2 & 19.1 & 775.2 & 172.9 & 60.1 \\
\hline 55Ç\$̧B16 & 9.2 & 14.6 & 0.5 & 205.0 & 372.1 & 4961.6 & 7121.7 & 121.3 & 28.7 & 826.0 & 219.7 & 39.4 \\
\hline 55ÇŞB17 & 9.0 & 13.8 & 0.5 & 170.0 & 286.3 & 4904.7 & 7262.7 & 86.9 & 14.7 & 812.4 & 292.9 & 41.8 \\
\hline 55ÇŞB19 & 9.0 & 14.4 & 0.6 & 221.0 & 263.8 & 5424.6 & 7743.6 & 158.6 & 10.1 & 1142.3 & 305.8 & 53.4 \\
\hline 55ÇŞB20 & 8.9 & 13.8 & 0.6 & 305.0 & 412.2 & 5350.6 & 7800.6 & 183.1 & 14.3 & 1357.5 & 381.0 & 70.0 \\
\hline 55ÇŞB21 & 8.9 & 14.8 & 0.7 & 280.0 & 435.7 & 4718.4 & 7132.3 & 191.0 & 19.0 & 1321.8 & 362.3 & 48.1 \\
\hline 55ÇŞB22 & 9.1 & 14.4 & 0.7 & 272.0 & 207.8 & 4898.3 & 7129.4 & 92.0 & 7.8 & 1198.0 & 279.9 & 57.3 \\
\hline 55ÇŞB23 & 9.0 & 13.8 & 0.7 & 302.0 & 243.7 & 5332.5 & 7702.5 & 154.8 & 10.9 & 1367.5 & 346.7 & 49.9 \\
\hline SÇKM & \multicolumn{6}{|c|}{ Suda çözünür kuru madde (\%) / Soluble solid contents } & GL & \multicolumn{5}{|c|}{ Glikoz (mg 100g-1)/ Glucose } \\
\hline $\mathrm{AK}$ & \multicolumn{6}{|c|}{ Antioksidan Aktivite (mmol $\left.100 \mathrm{~g}^{-1}\right)$ / Antioxidant activity } & FR & \multicolumn{4}{|c|}{ Fruktoz (mg 100g-1)/ Fructose } & \\
\hline $\mathrm{TF}$ & \multicolumn{6}{|c|}{ Toplam Fenol içeriği (mg 100g-1) / Total phonel content } & SA & \multicolumn{4}{|c|}{ Sitrik Asit (mg 100g-1) / Citric acid } & \\
\hline TA & \multicolumn{6}{|c|}{ Titreedilebilir asitlik (\%) / Titretable acidity } & MA & \multicolumn{4}{|c|}{ Malik Asit (mg 100g-1) / Malic acid } & \\
\hline $\begin{array}{l}\text { C Vit. } \\
\text { SAK }\end{array}$ & \multicolumn{6}{|c|}{ C Vitmaini (mg 100g-1)/ Vitamin $C$} & SÜA & \multicolumn{5}{|c|}{ Süksinik Asit (mg 100g-1) / Succinic acid } \\
\hline
\end{tabular}


Çizelge 5. Genotiplerin tartılı derecelendirmede almış oldukları puanlar

Table 5. "Weighted-Rankit" points of genotypes

\begin{tabular}{|c|c|c|c|c|c|}
\hline $\begin{array}{l}\text { Genotip } \\
\text { Genotype }\end{array}$ & $\begin{array}{c}\text { Meyve } \\
\text { Ağırliğı } \\
\text { Fruit weight } \\
\end{array}$ & $\begin{array}{l}\text { Meyve Eti } \\
\text { Oranı } \\
\text { Flesh ratio } \\
\end{array}$ & $\begin{array}{l}\text { Ağacın Verim } \\
\text { Potansiyeli } \\
\text { Yield potential }\end{array}$ & $\begin{array}{l}\text { Suda Çözünür Kuru } \\
\text { Madde } \\
\text { Soluble solid content }\end{array}$ & $\begin{array}{l}\text { TOPLAM } \\
\text { Total } \\
\text { point }\end{array}$ \\
\hline 55ÇŞB01 & 120 & 25 & 75 & 30 & 250 \\
\hline 55ÇŞB02 & 120 & 75 & 75 & 30 & 300 \\
\hline 55ÇŞB03 & 40 & 75 & 75 & 10 & 200 \\
\hline 55ÇŞB05 & 120 & 25 & 125 & 30 & 300 \\
\hline 55ÇŞB06 & 120 & 125 & 125 & 10 & 380 \\
\hline 55ÇŞB07 & 40 & 25 & 25 & 10 & 100 \\
\hline 55ÇŞB08 & 200 & 75 & 125 & 10 & $410(4)$ \\
\hline 55ÇŞB09 & 200 & 125 & 125 & 10 & $460(2)$ \\
\hline 55ÇŞB10 & 200 & 125 & 125 & 30 & 480 (1) \\
\hline 55ÇŞB11 & 200 & 125 & 25 & 10 & 360 \\
\hline 55ÇŞB12 & 200 & 125 & 75 & 50 & $450(3)$ \\
\hline 55ÇŞB13 & 200 & 25 & 125 & 50 & $400(5)$ \\
\hline 55ÇŞB15 & 40 & 25 & 125 & 50 & 240 \\
\hline 55ÇŞB16 & 40 & 25 & 75 & 50 & 190 \\
\hline 55ÇŞB17 & 40 & 25 & 75 & 50 & 190 \\
\hline 55ÇŞB19 & 40 & 75 & 25 & 50 & 190 \\
\hline 55ÇŞB20 & 40 & 25 & 75 & 50 & 190 \\
\hline 55ÇŞB21 & 40 & 75 & 125 & 50 & 290 \\
\hline 55ÇŞB22 & 120 & 75 & 75 & 50 & 320 \\
\hline 55ÇŞB23 & 120 & 75 & 25 & 50 & 270 \\
\hline
\end{tabular}

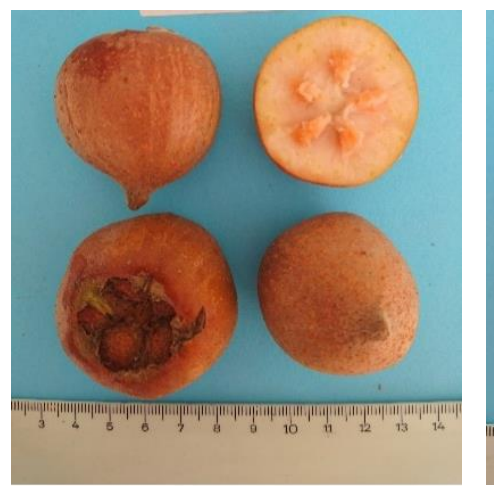

55ÇŞB08

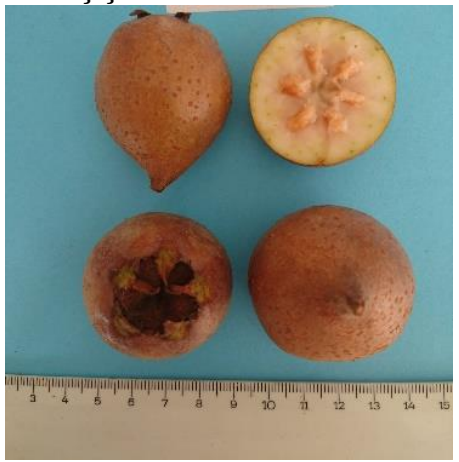

55 ÇŞB12

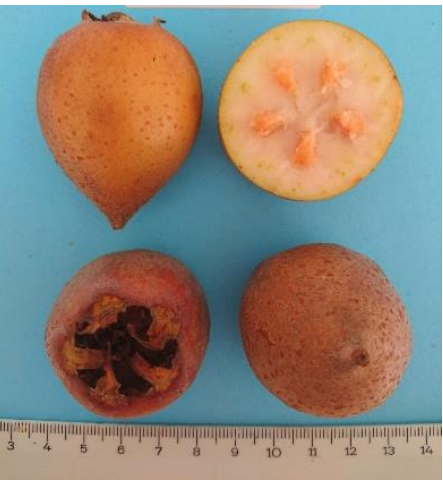

55ÇŞB09

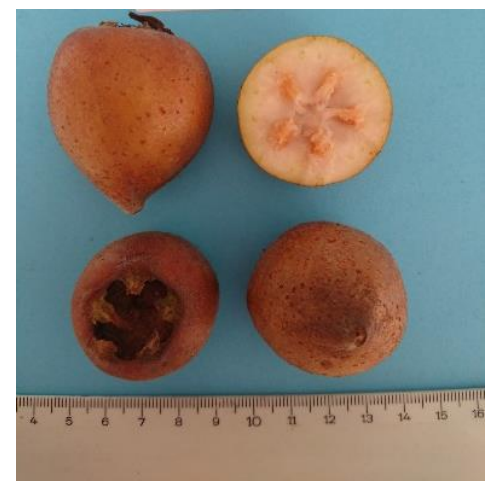

55ÇŞB10

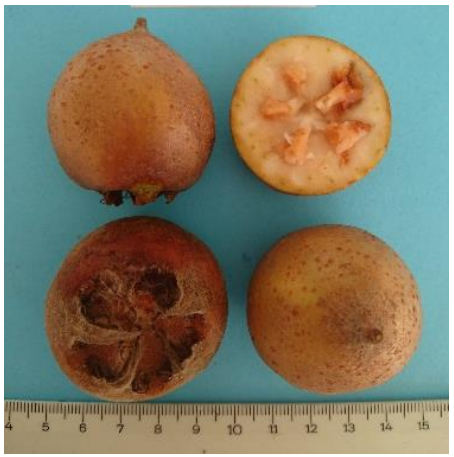

55ÇŞB13

Şekil 1. Ümitvar muşmula genotipleri

Figure 1. Promising medlar genotypes

genotip (Özkan ve ark., 1997), Orta ve Doğu Karadeniz bölgesinden 5 ümitvar genotip (Bostan, 2002), Ulubey (Ordu) ilçesinden 1 ümitvar genotip (Aygün ve Taşçı, 2013), Tokat merkez ilçe ve köylerinden 11 ümitvar genotip (Yılmaz, 2015), Tonya (Trabzon) ilçesinden 8 ümitvar genotip (Közen ve Bostan, 2016), Sürmene (Trabzon) ilçesinden 8 ümitvar genotip (Uzun ve Bostan, 2019), Terme (Samsun) ilçesinden 5 ümitvar genotip (Akın, 2019), Tekkeköy (Samsun) ilçesinden 3 ümitvar genotip (Çakır ve Öztürk, 2019), Giresun 
Merkez ilçeden 5 ümitvar genotip (Sarıyıldız, 2019) ve Aybastı (Ordu) ilçesinden 2 ümitvar genotip (Duman, 2019) değerlendirmeye alınmıştır. Diğer taraftan, Akçakoca (Düzce) ilçesindeki seleksiyon ıslahı çalışmaları ile "Akçakoca $77^{\circledR}$ " ismiyle 2014 yılında bir çeşit tescil edilmiştir (Akçay ve ark., 2016).

Çalışmada ümitvar görülen 5 çeşit adayı genotipin tartılı derecelendirmede dikkate alınan meyve ağırlığı, meyve eti oranı ve suda çözünür kuru madde miktarı özelliklerine ait değerler önceki çalışmalarla karşılaştırılmıştır. Bu çalışmada meyve ağırlığı $28.1 \mathrm{~g}$ ile $31.6 \mathrm{~g}$ arasında değişim göstermiştir. Bu değer daha önce yapılan çalışmalarda ümitvar olarak seçilen genotiplerde $15.99 \mathrm{~g}$ ile $37.20 \mathrm{~g}$ arasında değişmiştir (Özkan ve ark., 1997; Bostan, 2002; Yllmaz, 2015; Közen ve Bostan, 2016; Akın, 2019; Çakır ve Öztürk, 2019; Duman, 2019; Uzun ve Bostan, 2019, Sarıyıldız, 2019).

Çalışmada meyve eti oranı \%87.9 ile \%91.0 arasında değişim göstermiştir. $\mathrm{Bu}$ değer daha önce yapılan çalışmalarda ümitvar olarak seçilen genotiplerde \%78.71 ile \%94.7 arasında değişmiştir (Yılmaz, 2015; Közen ve Bostan, 2016; Akın, 2019; Çakır ve Öztürk, 2019; Duman, 2019; Uzun ve Bostan, 2019).

Çalışmada suda çözünür kuru madde miktarı \%10.4 ile \%15.2 arasında değişim göstermiştir. Bu değer daha önce yapılan çalışmalarda ümitvar olarak seçilen genotiplerde \%11.2 ile \%27.3 arasında değiş̧iştir (Özkan ve ark., 1997; Bostan, 2002; Yllmaz, 2015; Közen ve Bostan, 2016; Akın, 2019; Çakır ve Öztürk, 2019; Duman, 2019; Uzun ve Bostan, 2019; Sarıyıldız, 2019). İncelenen özellikler bakımından çeşit adayı genotiplerin önceki çalışma sonuçları ile benzerlik arz ettiği görülmektedir.

\section{SONUÇ ve ÖNERILER}

Çalışmada çeşit adayı olarak seçilen genotipler pomolojik özellikleri yönünden değer arz etmeleri yanında bulundukları bölgeler için, ekolojilerine iyi uyum sağlamış olmaları nedeniyle de büyük bir değere sahip olup bitki gen kaynaklarının korunması için de Türkiye açısından önem arz etmektedir.

Türkiyenin doğal bitki popülasyonu içinde yer alan ve özellikle kış hastalıklarına karşı dayanımı sağlayan şifa deposu olarak tanımlanan muşmulanın ünü Karadeniz sahil kuşağı ve iç kesimlerinden ileriye gidememiştir. Çok değerli olan bu meyve türünde yetiştiriciler hiç bir kültürel işlem yapmadıkları gibi bu çeşide ait düzenli ve kapama bir bahçeye de rastlanılmamıştır.

Çeşit adayı genotiplerde mevcut koşullarda bile meyve kalitesi yönünden önemli olan meye ağırlı̆̆ının 31.6 g'a ve meyve eti oranının \%91.0'e çıtığını; yeme kalitesi ile beslenme ve sağllk yönünden önemli olan C vitamini miktarının $36.7 \mathrm{mg} 100 \mathrm{~g}^{-1}$ 'a, fruktoz içeriğinin $7790.6 \mathrm{mg} 100 \mathrm{~g}^{-1}$ 'a, malik asit içeriğinin

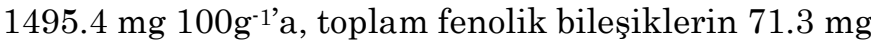
$100 \mathrm{~g}^{-1}$ 'a ve toplam antioksidan aktivitenin de 72.0 mmol 100g-1’a çıktığını düşündüğümüzde, bu genotiplerin gerçek performanslarını kültür koşullarında çok daha iyi düzeyde yansıtacaklarını söyleyebiliriz.

$\mathrm{Bu}$ gen kaynaklarımızın korunması ve çoğaltılması, yeni çeşit geliştirilmesi ile ekonomik olarak üretimi ve tüketimi bakımından oldukça önem arz etmektedir.

\section{TEŞEKKÜR}

Bu makale Ordu Üniversitesi Fen Bilimleri Enstitüsü Bahçe Bitkileri Anabilim Dalında Eda MARAL GÜRBÜZ tarafından tamamlanan Yüksek Lisans Tezinden hazırlanmış olup Bilimsel Araştırma Projeleri Komisyonunca kabul edilen BY-1728 nolu proje kapsamında desteklenmiştir. Desteklerinden dolayı ilgili kuruma ve birime teşekkür ederiz.

\section{Çıkar Çatışması Beyanı}

Makale yazarları aralarında herhangi bir çıkar çatışması olmadığını beyan ederler.

\section{Araştırmacıların Katkı Oranı Beyan Özeti}

Yazarlar makaleye eşit oranda katkı sağlamış olduklarını beyan ederler.

\section{KAYNAKLAR}

Akçay ME, Özdemir Y, Doğan A 2016. Muşmula Yetiştiriciliğinde Yeni Bir Çeşit Olan Akçakoca $77^{\circledR}$ 'nin Bazı Özelliklerinin Belirlenmesi. BAHÇE (Özel Sayı cilt:1) 45: 832-837.

Akın Y., Bostan SZ 2018. Chemical PreCharacterization of Medlar Genotypes in Terme District (Samsun, Turkey). International Journal of Environmental Research and Technology, 1(2):8-10.

Akın Y 2019. Samsun İli Terme İlçesi Muşmula Genotiplerinin Kimyasal ve Fiziksel Karakterizasyonu. Ordu Üniversitesi Fen Bilimleri Enstitüsü Bahçe Bitkileri Ana Bilim Dall, Yüksek Lisans Tezi, 36 sy.

Anonim 2018. https://www.bilgidoktoru.com/dongelmusmula-meyvesinin-faydalari.

Aygün A, Taşçı AR 2013. Some Fruit Characteristics of Medlar (Mespilus germanica L.) Genotypes Grown in Ordu, Turkey. Scientific Papers, Series B, Horticulture LVII: 149-151.

Bostan SZ 2002. Interrelationships among Pomological Traits and Selection of Medlar (Mespilus germanica L.) Types in Turkey. Journal American Pomological Society 56(4): 215-218.

Bostan SZ, İslam A 2007. Doğu Karadeniz Bölgesi Muşmulalarının (Mespilus germanica L.) Seleksiyon Yoluyla Islahı Üzerinde Araştırmalar. V. Ulusal Bahçe Bitkileri Kongresi 4-7.09.2007, Erzurum, (Cilt 1: Meyvecilik): 494-501. 
Canbay Seçilmiş H, Atay E, Oğüt S 2015. Determination of Fruit Characteristics, Fatty Acid Profile and Total Antioxidant Capacity of Mespilus germanica L. Fruit. Journal of Coastal Life Medicine 3(11); 930-933.

Cevahir G, Bostan SZ 2018. Antioxidant Capacity of Selected Some Medlar Genotypes (Mespilus germanica L.). International Journal of Environmental Research and Technology, 1(2): 6-7.

Çakır E, Öztürk A 2019. Samsun İli Tekkeköy İlçesinde Yetişen Ümitvar Muşmula Genotiplerinin Belirlenmesi. Uluslararası Tarım ve Yaban Hayatı Bilimleri Dergisi (UTYHBD) 5(2): 240-249.

Davis PH 1972. Flora of Turkey and East Aegean Islands. Vol. 4. The University Press. Edinburgh, pp. 657.

Demir Ö 2006. Muşmula (Mespilus germanica L.) Meyvelerinin Olgunlaşması Sirasındaki Polifenol Oksidazın Karakterizasyonu. Karadeniz Teknik Üniversitesi Fen Bilimleri Enstitüsü Biyoloji Ana Bilim Dalı, Yüksek Lisans Tezi, 63 sy.

Duman C 2019. Aybastı (Ordu) İçesinde Yetişen Ümitvar Muşmula (Mespilus germanica L.) Genotiplerinin Belirlenmesi. Ordu Üniversitesi Fen Bilimleri Enstitüsü Bahçe Bitkileri Ana Bilim Dalı, Yüksek Lisans Tezi, 55 sy.

Ekim T, Koyuncuoğlu M, Vural H, Duman İ, Aytaç Z, Adıgüzel N 2000. Türkiye Bitkileri Kırmızı Kitabı (Eğrelti ve Tohumlu Bitkiler). (Red Data Book of Turkish Plants (Preridophyta and Spermatophyta).TTKD, Barışcan Ofset. Ankara.

Ercisli S, Sengul M, Yildiz H, Sener D, Duralija B, Voca S, Dujmovic Purgar D 2012. Phytochemical and Antioxidant Characteristics of Medlar Fruits (Mespilus germanica L.). Journal of Applied Botany and Food Quality 85-90.

Gülçin I, Topal F, Öztürk Sarıkaya SB, Bursal E, Bilsel G, Gören AC 2011. Polyphenol Contents and Antioxidant Properties of Medlar (Mespilus germanica L.). Records of Natural Products 5 (3): 158-175.
Hacıseferoğulları H, Özcan M, Sonmete HM, Özbek O 2005. Some Physical and Chemical Parameters of Wild Medlar (Mespilus germanica L.) Fruit Grown in Turkey. Journal of Food Engineering 69: 1-7.

Közen P, Bostan SZ 2016. Trabzon İli Tonya İlçesinde Doğal Olarak Yetişen Muşmula Tiplerinin (Mespilus germanica L.) Seleksiyonu. International Multidisciplinary Congress of Eurasia July 11-13 2016 Odessa (Ukraine).

Özkan Y, Gerçekçioğlu R, Polat M 1997. Tokat Merkez İlçede Yetiştirilen Muşmula (Mespilus germanica L.) Tiplerinin Meyve Özelliklerinin Belirlenmesi Üzerine Bir Araştırma. Yumuşak Çekirdekli Meyveler Sempozyumu 2-5 Eylül 1997, Yalova. Sayfa: 123-129.

Phipps JB, O'Kennon RJ, Lance RW 2003. Hawthorns and Medlars. Royal Horticultural Society, Cambridge, U.K.

TÜİK 2020. https://biruni.tuik.gov.tr/ medas/ ?locale=tr.

Sarıyıldız, S 2019. Giresun İli Merkez İlçede Doğal Olarak Yetişen Muşmula Genotiplerinin (Mespilus germanica L.) Seleksiyonu. Ordu Üniversitesi Fen Bilimleri Enstitüsü Bahçe Bitkileri Ana Bilim Dalı, Yüksek Lisans Tezi, 38 sy.

Uzun M, Bostan SZ 2014. Sürmene İlçesinde (Trabzon) Doğal Olarak Yetişen Muşmula Genotiplerinin (Mespilus germanica L.) Seleksiyonu. Iğdır Üniversitesi Fen Bilimleri Enstitüsü Dergisi 9(2): 604-613.

Yllmaz A 2015. Tokat'ta Doğal Olarak Yetişen Muşmula (Mespilus germanica L.) Genotiplerinin Seleksiyonu. Gaziosmanpaşa Üniversitesi Fen Bilimleri Enstitüsü Bahçe Bitkileri Anabilim Dalı, Doktora Tezi, 115 sy.

Yılmaz A, Gerçekçioğlu R 2013. Tokat Ekolojisi Muşmula (Mespilus germanica L.) Popülasyonu ve Dağılımı Üzerine Bir Araştırma. Tarım Bilimleri Araştırma Dergisi 6 (2): 01-04. 